\title{
Differential Effects of Abnormal Tactile Experience on Shaping Representation Patterns in Developing and Adult Motor Cortex
}

\author{
George W. Huntley \\ Fishberg Research Center for Neurobiology, The Mount Sinai School of Medicine, New York, New York 10029-6574
}

This study investigates the influence of early somatosensory experience on shaping movement representation patterns in motor cortex. Electrical microstimulation was used to map bilaterally the motor cortices of adult rats subjected to altered tactile experience by unilateral vibrissa trimming from birth (birth-trimmed group) or for comparable periods that began in adulthood (adult-trimmed group). Findings demonstrated that (1) vibrissa trimming from birth, but not when initiated in adulthood, led to a significantly smaller-sized primary motor cortex (M1) vibrissa representation in the hemisphere contralateral to the trimmed vibrissae, with no evidence for concomitant changes in size of the adjacent forelimb representation or the representation of the intact vibrissae in the opposite (ipsilateral) hemisphere; (2) in the contralateral hemispheres of the birthtrimmed group, an abnormal pattern of evoked vibrissa movement was evident in which bilateral or ipsilateral (intact) vibrissa movement predominated; (3) in both hemispheres of the birthtrimmed group, current thresholds for eliciting movement of the trimmed vibrissa were significantly lower than normal; and (4) in the adult-trimmed group, but not in the birth-trimmed group, there was a decrease bilaterally in the relative frequency of dual forelimb-vibrissa sites that form the common border between these representations. These results show that sensory experience early in life exerts a significant influence in sculpting motor representation patterns in $\mathrm{M} 1$. The mature motor cortex is more resistant to the type and magnitude of influence that tactile experience has on developing $\mathrm{M} 1$, which may indicate that such an influence is constrained by a developmentally regulated critical period.

Key words: motor cortex; rat; vibrissa; plasticity; development; intracortical microstimulation
The primary motor cortex (M1) contains a topographic map of contralateral musculature or movements that is highly variable across individuals and between hemispheres (Sessle and Wiesendanger, 1982; Huntley and Jones, 1991; Donoghue et al., 1992; Nudo et al., 1992). The size and configuration of M1 maps change during motor skill acquisition (Jenkins et al., 1994; Karni et al., 1995; Pascual-Leone et al., 1995; Nudo et al., 1996), suggesting a close association between motor map organization and motor skill performance. Understanding the factors that influence motor cortical maps is therefore important for understanding the dynamic capacities of motor cortex function.

Tactile experience plays a significant role in shaping representational maps in somatosensory cortex (S1) (Clark et al., 1988). Adult rats in which mystacial vibrissae are trimmed from infancy possess S1 neurons with abnormal receptive fields (Simons and Land, 1987; Fox, 1992) and display behavioral impairments in certain types of vibrissa-related tactile discrimination (Carvell and Simons, 1996). These abnormalities reflect a disruption in the normal spatiotemporal patterns of activity, which arise from the vibrissae as they are rhythmically moved across objects encountered during exploratory behavior (Guic-Robles et al., 1989; Carvell and Simons, 1990; Nicolelis et al., 1995). The anatomical

\footnotetext{
Received July 22, 1997; revised Sept. 22, 1997; accepted Sept. 22, 1997.

This research was supported by Grant NS34659 from the National Institutes of Health, United States Public Health Service; an Irma T. Hirshl Career Scientist Award; and the Eastern Paralyzed Veterans Association. I thank Stephanie Cohen for expert technical assistance and Drs. Deanna L. Benson and Adam H. Gazzaley for invaluable discussion and helpful criticism.

Correspondence should be addressed to Dr. George W. Huntley, Box 1065/ Neurobiology, The Mount Sinai School of Medicine, One Gustave L. Levy Place, New York, NY 10029-6574.

Copyright (C) 1997 Society for Neuroscience $\quad 0270-6474 / 97 / 170001-13 \$ 05.00 / 0$
}

basis for these deficits may involve altered inhibitory (Micheva and Beaulieu, 1995a,b) and excitatory circuitry (Fox, 1994; Dolan and Cahusac, 1996) within S1. The capacity for experiencedependent modifications of S1-receptive fields persists into adulthood (Diamond et al., 1993), although effects of tactile deprivation change with increasing maturity (Fox, 1992).

Many aspects of motor cortex function depend on somatosensory input. The functional properties of M1 neurons are strongly influenced by somatosensory feedback (Lemon and Porter, 1976; Zarzecki, 1989), and stimulation-evoked output from M1 can change on readjustments of limb position, a manipulation that presumably changes proprioceptive feedback (Gellhorn and Hyde, 1953; Sanes et al., 1992). Corresponding parts of representational maps in S1 and M1 are topographically linked by dense corticocortical connections (Jones et al., 1978; Izraeli and Porter, 1995); such connectivity is critical for learning new motor skills (Pavlides et al., 1993) and can display activity-dependent changes in functional efficacy (Sakamoto et al., 1987). The close functional and anatomical relationship between motor and somatosensory cortical maps raises the possibility that the influence of tactile experience on developing representational maps in S1 extends to those of developing motor cortex. This hypothesis is consistent with peripheral lesion studies showing that forelimb removal on the first day of life results in adult motor maps with novel organizational features (Donoghue and Sanes, 1988). What role sensory experience plays in such effects, however, is unclear, because target degeneration-induced factors may also be involved. Therefore, in this study the effects of abnormal tactile experience on the development and maintenance of motor cortex representations were examined bilaterally in adult rats in which vibrissae were clipped unilaterally either from birth or for com- 


\begin{tabular}{|c|c|c|c|c|c|}
\hline \multirow[b]{2}{*}{ Group } & \multirow[b]{2}{*}{ Animal } & \multirow[b]{2}{*}{ Sex } & \multicolumn{3}{|c|}{ Whisker trim } \\
\hline & & & $\begin{array}{l}\text { Age start } \\
\text { (PND) }\end{array}$ & $\begin{array}{l}\text { Duration } \\
\text { (d) }\end{array}$ & $\begin{array}{l}\text { Age mapped } \\
\text { (PND) }\end{array}$ \\
\hline \multirow[t]{10}{*}{ Birth-trimmed } & R144 & $\mathrm{F}$ & 1 & 48 & 55 \\
\hline & R145 & M & 1 & 55 & 62 \\
\hline & R146 & M & 1 & 63 & 70 \\
\hline & $\mathrm{R} 147$ & M & 1 & 74 & 81 \\
\hline & R148 & M & 1 & 87 & 94 \\
\hline & R149 & $\mathrm{F}$ & 1 & 87 & 94 \\
\hline & $\mathrm{R} 150$ & $\mathrm{~F}$ & 1 & 87 & 94 \\
\hline & $\mathrm{R} 157$ & M & 1 & 87 & 94 \\
\hline & R158 & M & 1 & 117 & 124 \\
\hline & R162 & M & 1 & 117 & 124 \\
\hline Average & & & 1 & 82.2 & 89.2 \\
\hline \multirow[t]{6}{*}{ Adult-trimmed } & $\mathrm{R} 151$ & $\mathrm{~F}$ & 48 & 117 & 172 \\
\hline & $\mathrm{R} 152$ & $\mathrm{~F}$ & 48 & 114 & 169 \\
\hline & $\mathrm{R} 153$ & M & 50 & 85 & 142 \\
\hline & $\mathrm{R} 154$ & M & 52 & 74 & 133 \\
\hline & $\mathrm{R} 155$ & M & 54 & 62 & 123 \\
\hline & R156 & M & 54 & 51 & 112 \\
\hline Average & & & 51 & 83.8 & 141.8 \\
\hline \multirow[t]{4}{*}{ Adult-control } & R174 & M & & & 79 \\
\hline & R176 & M & & & 82 \\
\hline & R177 & $\mathrm{F}$ & & & 96 \\
\hline & R178 & $\mathrm{F}$ & & & 127 \\
\hline Average & & & & & 96 \\
\hline
\end{tabular}

parable periods beginning in adulthood. The advantage of this paradigm is that it is noninvasive, producing no structural degeneration of the trigeminal nerve or follicles (Li et al., 1995).

\section{MATERIALS AND METHODS}

Animals. This study was conducted on the brains of 20 Sprague Dawley rats, the sexes and rearing histories of which are provided in Table 1. Pregnant mothers were obtained commercially and monitored at $12 \mathrm{hr}$ intervals around the expected parturition time. The litters of these animals served as the experimental subjects for the study and were divided into three groups: (1) a birth-trimmed group $(n=10)$, in which unilateral vibrissa trimming started on postnatal day (PND) 1 (defined as the period between the first 12-24 hr after birth) and continued on a daily basis until adulthood (defined as PND 45 or older); (2) an adulttrimmed group $(n=6)$, in which unilateral vibrissa-trimming began when animals reached adulthood and continued on a daily basis for periods comparable to those of the birth-trimmed group; and (3) an adult-control group $(n=4)$, which served as a normative database against which the other groups were compared.

Vibrissa-trimming procedure and controls. For all experimental subjects, animals were gently restrained by hand while the mystacial vibrissae on the right side of the face were clipped uniformly, using iridectomy scissors, to within $0.5-1 \mathrm{~mm}$ from the skin surface. The vibrissae on the left side were left intact. Animals adapted quickly to being handled, which made anesthesia unnecessary for this procedure. Vibrissae were allowed to regrow for $7 \mathrm{~d}$ before mapping the motor cortex to facilitate detection of vibrissa movements. The four control animals were handled daily in a manner similar to those of the other groups; opened scissors were moved through their vibrissae, but they were not trimmed.

Electrical stimulation mapping of M1 movement representations. The treatment of all animals was in strict accordance with Institutional Animal Care and Use Committee guidelines. In preparation for mapping, animals were anesthetized with a mixture of ketamine $\mathrm{HCl}(40$ $\mathrm{mg} / \mathrm{kg}, \mathrm{i} . \mathrm{m}$.) and xylazine $(8 \mathrm{mg} / \mathrm{kg}, \mathrm{i} . \mathrm{m}$.) and placed into a stereotaxic instrument. For the duration of the experiment, supplemental doses of anesthetic were given periodically to suppress hindlimb withdrawal, and body temperature was maintained at $36-38^{\circ} \mathrm{C}$ with a heat lamp. Under aseptic conditions, large craniotomies were made bilaterally over the sensorimotor cortex, the midpoint of which was at bregma. The dura was left intact and kept moist with warmed mineral oil or saline.

The output organization of M1 was determined bilaterally by documenting movements elicited by standard electrical stimulation techniques (Huntley and Jones, 1991; Huntley, 1997). In one-half of the animals of each group, the left M1 was mapped first, followed by mapping of the right M1; the order was reversed for the remaining half. To delineate movement representations, a tungsten microelectrode (impedance, 1-1.2 $\mathrm{M} \Omega$ at $1 \mathrm{kHz}$ ) was inserted perpendicularly into the cortex approximately to the depth of layer $\mathrm{V}$ (1.5-1.8 $\mathrm{mm}$ from the pial surface), and current trains (11 monophasic cathodal pulses, 0.2 msec duration at $330 \mathrm{~Hz}$ ) were passed every $2 \mathrm{sec}$. At each site, an initial current intensity of $60 \mu \mathrm{A}$ was used to evoke movements or muscle twitches, which were observed by visual inspection or muscle palpation. This maximal current value was not exceeded to prevent damage that can occur at higher intensities (Asanuma and Arnold, 1975). Current level was then progressively lowered until current threshold was reached, defined as the level at which approximately one-half of the current trains elicited movement or muscle twitches. If no movements or twitches were evoked with $60 \mu \mathrm{A}$, the site was recorded as negative. Mindful that variability in threshold currents can occur with fluctuations in anesthetic levels, mapping was suspended during periods when currents required to evoke movement at several arbitrarily chosen reference stimulation sites, which were continuously retested during the mapping session, deviated by $>3-5 \mu \mathrm{A}$ from threshold levels determined for those sites initially. The type of movement remained constant when sites were retested over time, suggesting that the general topography of movement maps were quite stable over the mapping period, similar to previous observations in monkeys (Nudo et al., 1996). The microelectrode was advanced in a grid-like pattern, each track $\sim 250-300 \mu \mathrm{m}$ apart. This pattern was occasionally interrupted by surface vasculature, necessitating larger deviations of electrode position. The location of each microelectrode site was plotted on a drawing of surface vasculature, and all movement evoked at that site was noted, and the coordinates of each penetration were recorded from the micromanipulator. Forelimb and hindlimb joints were alternately flexed and extended on occasion, particularly when defining representation borders, 
to expose the fullest extent of the representation of that limb by minimizing positional bias in evoked output (Sanes et al., 1992). The term "forelimb movement" used throughout this study refers collectively to movement of the digits, or about the wrist, elbow, and shoulder. At some sites, movements of two different body parts were elicited simultaneously (e.g., forelimb and vibrissa). Such sites are hereafter termed dualmovement sites, and both movements were recorded for that position regardless of the individual thresholds, which were determined separately for each. For bilateral whisker movements, current thresholds were tallied separately for the ipsilateral and contralateral components. At the end of the mapping session, animals were perfused transcardially, and the brains were cryoprotected, sectioned, and stained with thionin, all according to procedures described previously (Huntley, 1997). Thioninstained sections were examined to verify microelectrode positions and depths.

The technical limitations of using electrical microstimulation to delineate the fine organization of functional M1 motor representations have been discussed previously (Huntley and Jones, 1991; Nudo et al., 1992). There are several observations that suggest that intracortical microstimulation-generated output is a reasonable reflection of functional organization at discrete M1 sites. In awake animals there is a strong correlation between the location of an M1 site from which singlepulse intracortical microstimulation produces contraction of a set of muscles and the location of neurons with activity that is associated with naturally occurring movement involving the same muscles (Cheney and Fetz, 1985; Lemon et al., 1987). Although trains of stimuli, such as those used in the present study, can produce different patterns of recruitment, most penetrations from which current trains are passed yield movement of a single body part; the movement of different body parts can occur with as little as $\sim 100 \mu \mathrm{m}$ displacement of electrode position. These observations would suggest that activation of distantly located output neurons by direct current spread, transynaptically, or by engaging widespread afferent or intrinsic axons is minimal (Asanuma et al., 1976; Ezure and Oshima, 1985).

Data analysis: determination of representation sizes. Surface view plots of the positions of all microelectrode penetrations for each hemisphere were constructed using graphing software (Kaleidograph) based on the coordinates of each site recorded during the mapping session with bregma as a standard $(0,0)$ reference point. A boundary circumscribing the entire area from which movement of a given body part was elicited was drawn onto these computer-generated plots by enclosing all sites from which movement of that body part was evoked at $\leq 60 \mu \mathrm{A}$. For movement of any given body part, borderlines were placed at the midpoint between any two electrode penetrations in which movement of that body part was obtained from one penetration, either solely or as part of a dual movement, whereas from the other penetration, movement of a different body part was elicited, or no movement was evoked with the highest current intensity used $(60 \mu \mathrm{A})$. The total areal extent of individual forelimb and vibrissa representations was determined with image analysis software (NIH Image, version 1.61) by analyzing identically scaled images of each map. Only the areal extents of the vibrissa and forelimb representations were determined, because: (1) it was expected that vibrissa trimming could affect the size of the vibrissa representation; (2) the forelimb representation shares the longest, common border with the vibrissa representation in comparison with any other neighboring M1 representation; and (3) there is previous evidence that the position of the forelimb-vibrissa border can change under a variety of peripheral manipulations (e.g., Donoghue et al., 1990; Sanes et al., 1992), thus leading to the possibility of reciprocal changes in size of both representations. For each group, the resulting sizes of individual forelimb and vibrissa representations for each animal comprising that group were used for two types of analysis: (1) within-group comparisons between the left experimental hemisphere (defined as M1 contralateral to the trimmed vibrissae) and the right hemisphere (defined as M1 ipsilateral to the trimmed vibrissae), in which statistically significant differences in mean size were determined using paired Student's $t$ tests (level of significance, $p<0.05$ ) and (2) across-group comparisons between left experimental hemispheres or right hemispheres, in which statistically significant differences were determined using one-way ANOVA and a Scheffé's post hoc test (level of significance, $p<0.05$ ).

Movement maps shown schematically (see Fig. 1) were prepared identically, except that, for simplification, borders were drawn through dual-movement sites.

There are several potential sources of variability that could affect the sizes of representations determined by the methods used. Significant differences in density of penetrations (mapping density) would affect relative accuracy of border placement, thus influencing the overall configuration (and size) of map contours. Therefore, similar mapping densities were maintained across groups (see Results). Variability could arise from differences in the extent to which movement representations extended laterally, because increasing curvature of the brain would lead to increasingly oblique microelectrode traverses and distortions between the position of microelectrode entry on the surface, where coordinates are recorded, and the position of the tip in layer $\mathrm{V}$, where output is evoked. Histological examination of sections from each group of animals confirmed a 100-200 $\mu \mathrm{m}$ discrepancy between the surface position of the most laterally situated tracks and their tip position in layer V. If in one group, for example, a given movement representation was composed, on average, of a greater proportion of laterally situated sites, then the mean size of that representation would be underestimated in comparison with the other groups. This would affect principally the forelimb representation, which normally occupies the most lateral position in rat M1. To determine whether there were any differences across groups in the proportion of laterally situated sites, a mediolateral frequency distribution of forelimb and vibrissa sites was plotted as described by Sanes et al., (1990). The mediolateral dimension across the cortex was divided into 0.5 -mm-wide bins (starting from the midline and extending $5.5 \mathrm{~mm}$ laterally) into which all sites eliciting forelimb or vibrissa movement were grouped, irrespective of anteroposterior coordinate (see Results, Fig. 3). For each bin, the number of tracks was tallied and converted to frequency by expressing data as a percentage of the total number of tracks for that movement. Statistical analyses (ANOVAs) across groups for each bin revealed no significant differences across groups in the relative proportion of sites distributed mediolaterally from which vibrissa or forelimb movements were evoked. Thus, the mean sizes of the forelimb and vibrissa representations for each group would be affected to the same extent by any underestimations imposed by the lateral-most tracks. Because the goal of this study was to document effects on relative sizes of representations, with consideration of true sizes of minor importance, no attempt was therefore made to correct for any potential distortion.

Although ideally, unbiased stereological methods should be applied to yield the most accurate estimates of motor representation size, a number of factors render the application of such techniques unfeasible. First, unbiased estimates of surface area require random vertical axis rotation of the tissue block before sectioning (Baddeley et al., 1986), which would preclude accurate electrode reconstruction and therefore reliable determination of individual movement representations. Second, the accuracy of estimating the volume of cortex devoted to a particular movement representation using unbiased stereological methods would remain limited by representational boundaries defined by extrapolating between two electrode tracks, because no neurochemical markers or unique cytoarchitectonic features have yet been identified that unambiguously delineate individual movement representations within rat M1.

\section{RESULTS}

Both birth-trimmed and adult-trimmed animals displayed natural whisking movement as they explored freely in their cages. This observation suggests little or no mystacial muscle pad damage or atrophy as a result of vibrissa trimming, which is consistent with previous conclusions (Carvell and Simons, 1996).

\section{Effects on sizes of motor representations}

In adult-control (untrimmed) rats, 629 penetrations were made into the motor cortices of eight hemispheres (average, 78.6 penetrations per hemisphere; mapping density, 3.82 penetrations per square millimeter), with $73.3 \%$ of these sites eliciting movement with currents $\leq 60 \mu \mathrm{A}$. The general topographic organization and boundary relations of the M1 motor representations were similar among all animals of the control group and consistent with previous descriptions of rat M1 (for review, see Wise and Donoghue, 1986). In general, the vibrissa representation occupied an elongated, anteroposteriorally oriented strip, which formed a relatively long and undulating border with the adjacent, laterally situated forelimb representation (Fig. $1 A$ ). Both the vibrissa and forelimb representations in different animals exhibited considerable variation in overall configuration (Fig. 1 $A$ ) and size (range: 
vibrissa, 3.9-6.1 $\mathrm{mm}^{2}$; forelimb, 6.1-9.9 $\mathrm{mm}^{2}$ ). However, quantitative analysis of the control group revealed that there were no significant differences between left and right hemispheres in the mean sizes of the M1 vibrissa (Fig. 2A) or forelimb (Fig. 2B) representations.

In the adult-trimmed group of animals, 894 electrode penetrations were made into the motor cortices of 12 hemispheres (average, 74.5 penetrations per hemisphere; mapping density, 3.55 penetrations per square millimeter), with $71.3 \%$ of these sites eliciting movement with currents $\leq 60 \mu \mathrm{A}$. The general topographic organization and boundary relations of the M1 representations were similar to those of the control group (Fig. 1B). In addition, both vibrissa and forelimb representations also displayed variability in overall configuration (Fig. 1B) and size (range: vibrissa, 3.0-4.8 $\mathrm{mm}^{2}$; forelimb, 5.3-8.9 $\mathrm{mm}^{2}$ ). Qualitative and quantitative comparisons between left experimental and right hemispheres of the adult-trimmed animals showed no significant differences in the mean sizes of the vibrissa or forelimb representations after the period of vibrissa trimming (Figs. $1 B$, 2). In comparison with the adult-control group, the mean sizes of the vibrissa representations in both hemispheres were slightly, but not significantly, smaller (Fig. $2 A$ ), whereas the mean sizes of the forelimb representations were similar (Fig. $2 B$ ). Thus, there was no evidence that unilateral vibrissa trimming for a period that began and ended in adulthood produced significant changes in the mean sizes of the vibrissa or forelimb representations of either hemisphere.

In the birth-trimmed group of animals, 1389 microelectrode penetrations were made into the motor cortices of 20 hemispheres (average, 69.5 penetrations per hemisphere; mapping density, 3.88 penetrations per square millimeter), with $69.3 \%$ of these sites eliciting movement with currents $\leq 60 \mu \mathrm{A}$. Vibrissa movements were evoked reliably from either hemisphere after prolonged periods of vibrissa trimming from birth (detailed below), and, in general, the boundary relations of the M1 forelimb and vibrissa representations in both left and right hemispheres appeared similar to those of the control and adult-trimmed groups (Fig. 1C). However, in contrast to the other two groups of animals, the sizes of the vibrissa representations in the left experimental hemispheres of the birth-trimmed group were considerably smaller in comparison with those in the opposite (right) hemispheres (Fig. 1C, arrows; range: left, 1.7-4.2 $\mathrm{mm}^{2}$; right, $3.5-5.9 \mathrm{~mm}^{2}$ ). Quantitative comparisons of the mean sizes of the vibrissa representations verified that those of the left experimental hemisphere were, on average, $40.4 \%$ smaller than those of the right hemisphere, which was a significant difference (Fig. $2 A ; p<$ $0.05)$. To determine whether the difference in the mean size of the vibrissa representation between the two hemispheres was attributable to a shrinkage in the size of the vibrissa representations in the left experimental hemispheres, an increase in the size of the vibrissa representations in the right hemispheres, or both, the mean sizes of the vibrissa representations in the left and right hemispheres of the birth-trimmed group were compared with those of the corresponding hemispheres in the adult-control and adult-trimmed groups. Such across-group comparisons (Fig. 2A) demonstrated that the mean size of the vibrissa representation of the left experimental hemisphere was, on average, $45.1 \%$ smaller than that of the adult-control group (Fig. $2 A ; p<0.01$ ). In contrast, there were no significant differences across groups in the mean sizes of the vibrissa representation in the right hemispheres.

Despite the overt shrinkage in the size of the vibrissa repre- sentation of the left experimental hemisphere, vibrissa trimming from birth had no apparent effect on the mean size of the forelimb representation of either hemisphere (Figs. 1C, 2B; range: forelimb, 5.1-10.6 $\mathrm{mm}^{2}$ ); such values were not significantly different from those obtained from the other two groups of animals (Fig. 2B).

The cortex medial to the shrunken vibrissa representation of the left experimental hemispheres was not rigorously explored. In normal animals, this cortex is occupied by a small representation of the eye and eyelid. Although such evoked movements were occasionally observed in the birth-trimmed animals, they were not systematically mapped. However, the overall impression was that much of this cortex failed to produce any overt movement under the stimulating conditions imposed.

\section{Effects on relative positioning of motor representations}

The significantly smaller vibrissa representation in the left hemispheres of the birth-trimmed group raised the question of whether vibrissa trimming from birth also influenced the relative mediolateral positioning of the forelimb and vibrissa representations. Thus, the mean percentages of penetrations from which vibrissa or forelimb movement was evoked were plotted as a function of mediolateral position, irrespective of the anteroposterior coordinate (see Materials and Methods). Figure 3 demonstrates that for each group, considerable variation in the relative mediolateral positioning of the vibrissa (Fig. $3 A$ ) and forelimb (Fig. 3B) representations was apparent in both hemispheres. Statistical comparisons across the three groups revealed no significantly consistent differences between any of the groups in the relative mediolateral positioning of the vibrissa and forelimb representations.

\section{Effects on types of evoked vibrissa movements}

In adult-control animals, the mean frequencies of evoking contralateral, bilateral, or ipsilateral vibrissa movements were similar between right and left hemispheres (Fig. 4A,D), with the vast majority of penetrations $(92 \%)$ yielding contralateral vibrissa movement.

In the adult-trimmed group, the mean frequencies of evoked contralateral, bilateral, or ipsilateral vibrissa movements in the right hemisphere were virtually identical to those in the adultcontrol group (Fig. 4B). However, in the left experimental hemisphere, the mean frequency of evoking contralateral vibrissa movement dropped to $\sim 67 \%$ ( $p<0.05$, ANOVA), whereas the mean percentages of evoked bilateral and ipsilateral movements increased slightly (Fig. $4 E$ ) but not significantly ( $p=0.072$ ).

In the birth-trimmed group, the mean frequencies of evoked contralateral, bilateral, and ipsilateral vibrissa movements in the right hemisphere were also similar to those in the right hemispheres of both the adult-control and adult-trimmed groups (Fig. $4 C$ ). However, in the left experimental hemisphere the effects of vibrissa trimming on the type of evoked vibrissa movement were far more severe in comparison with those in the adult-trimmed group (Fig. $4 F$ ). Eliciting the normal pattern of contralateral vibrissa movement was rare, a significant deviation from control animals $(p<0.0001)$, whereas evoked bilateral movements increased substantially to $\sim 84 \%$ ( $p<0.0001)$ to become the predominant output. The percentage of penetrations yielding ipsilateral vibrissa movement also increased, to $14 \%$, in the left experimental hemisphere, which was a significantly greater value in comparison with that obtained from the right hemisphere of the same group $(2.1 \% ; p<0.05$, paired Student's $t$ test $)$ but which 
A

\section{Adult-control}

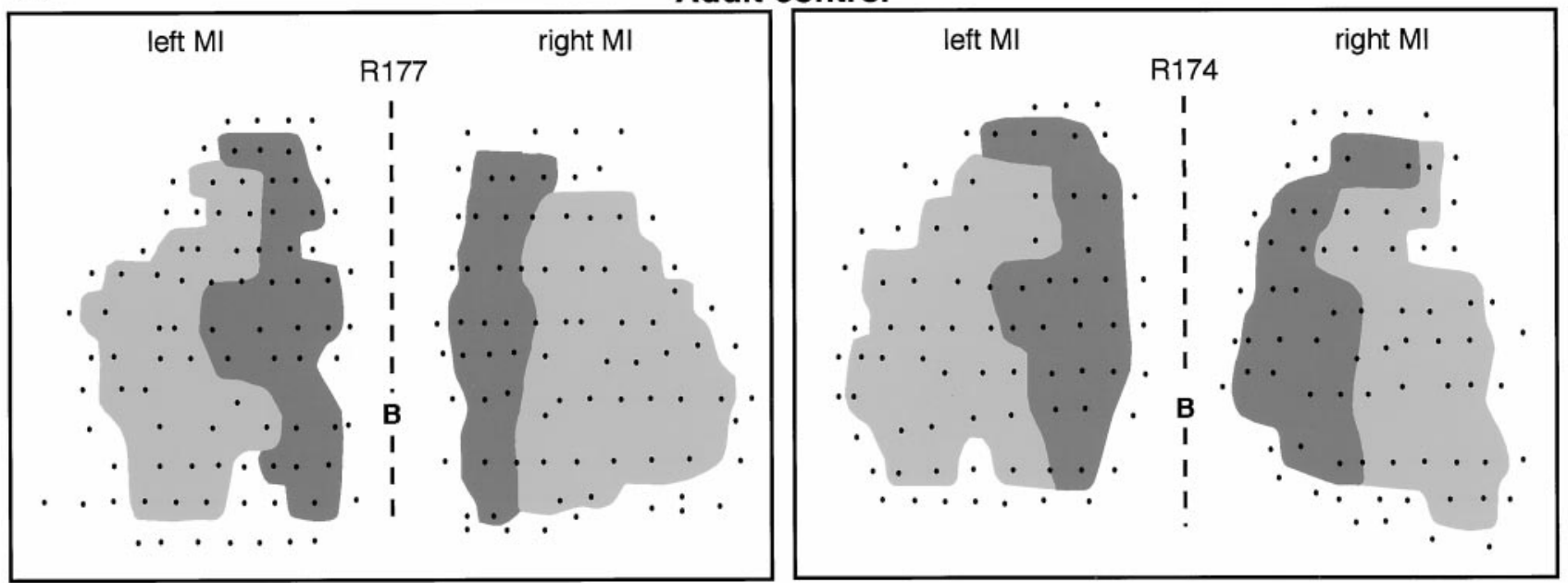

B

Adult-trimmed

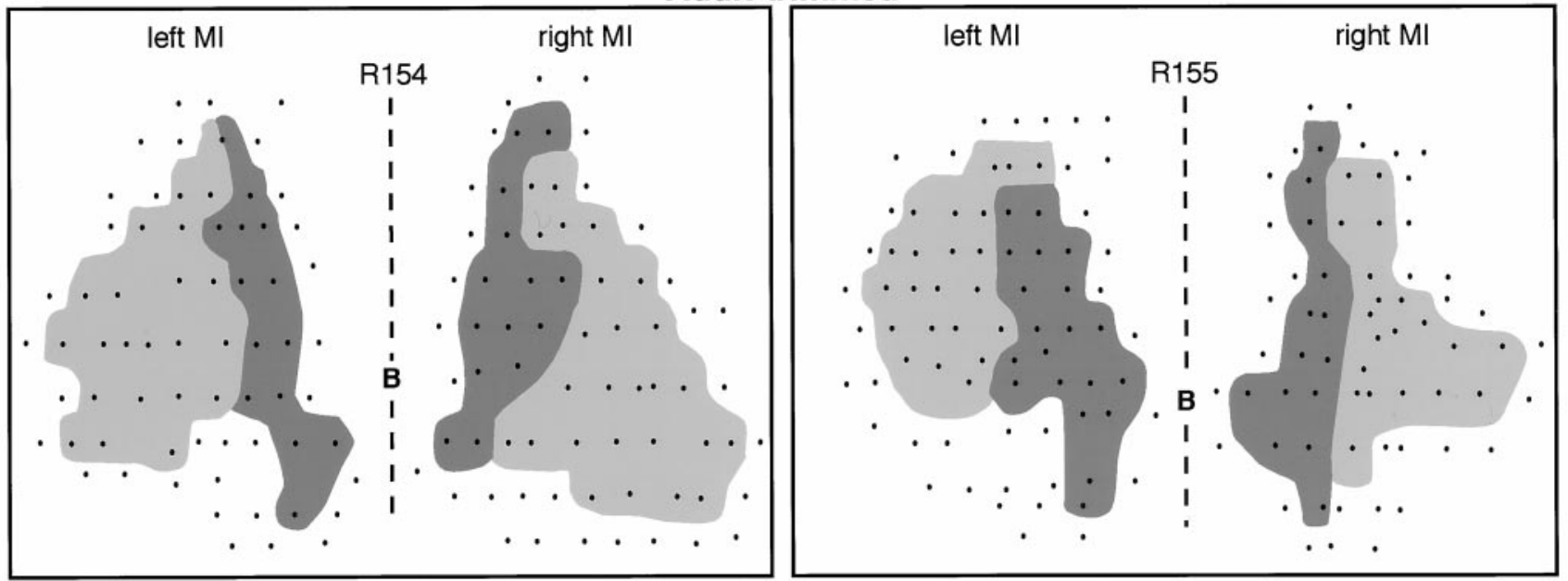

C

\section{Birth-trimmed}

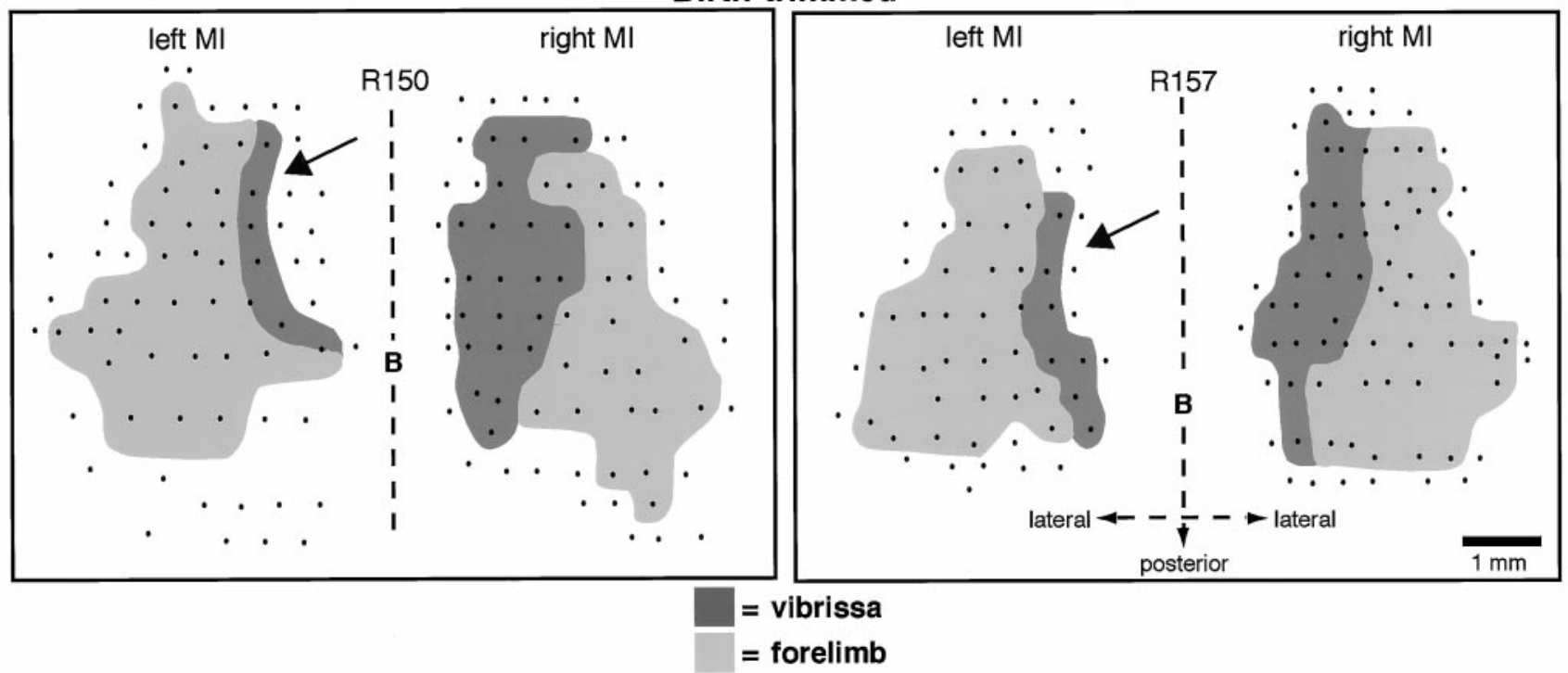

Figure 1. Surface view maps of M1 vibrissa and forelimb movement representations in adult-control $(A)$, adult-trimmed $(B)$, and birth-trimmed $(C)$ animals. For each group, M1 maps of the left experimental and right hemispheres are shown for two representative animals and illustrate both the individual variation in size and configuration of these movement representations and the effects of vibrissa trimming on the vibrissa representations in the left experimental hemispheres of the birth-trimmed group $(C$, arrows). The dashed lines between left and right hemispheres represent the positions of the midlines; $B$, position of bregma; dots, positions of microelectrode penetrations. 
A

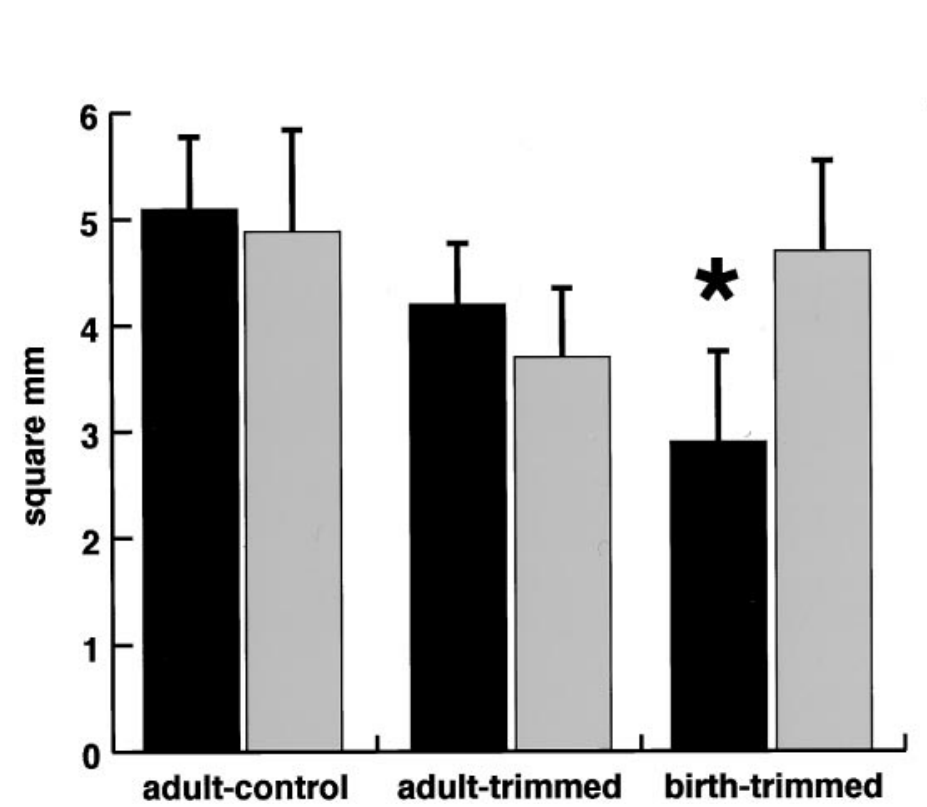

B
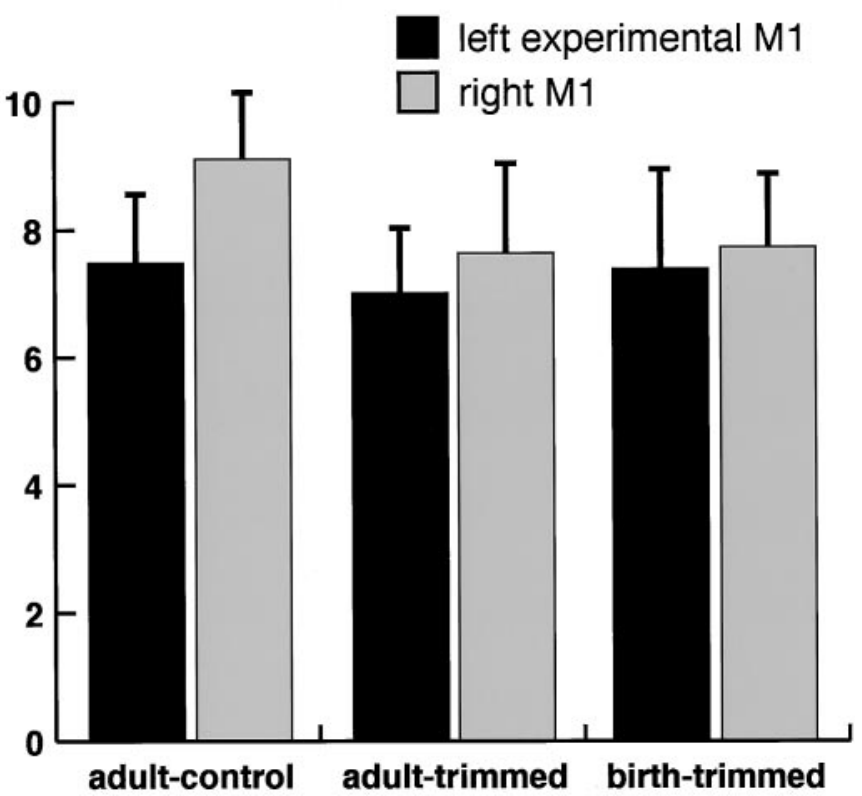

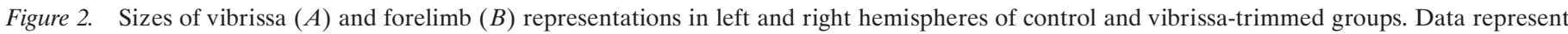

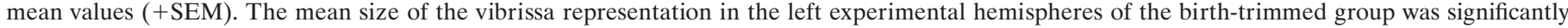

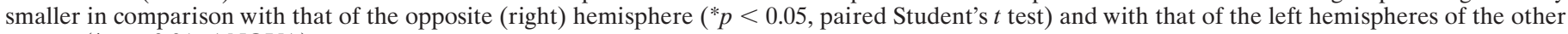
groups $\left({ }^{*} p<0.01\right.$, ANOVA).

was not significantly different from either of the other two groups in across-group comparisons.

\section{Effects on current thresholds of evoked movements}

Current thresholds for evoking movement of the trimmed or the intact vibrissae were compared across groups for each hemisphere. Such comparisons revealed that in the birthtrimmed group, the mean current threshold for evoking movement of the trimmed vibrissae, from either the left experimental hemisphere (Fig. $5 A$ ) or the right hemisphere (Fig. $5 C$ ), was significantly lower in comparison with the adult-trimmed or adult-control groups ( $p<0.05$, ANOVA). In contrast, there were no significant differences across groups in the mean thresholds for evoking movement of the intact vibrissae from either hemisphere (Fig. 5B,D).

The effects of vibrissa trimming on current thresholds appeared to be specific for the vibrissa, because there were no differences between hemispheres, or across groups, in the mean current thresholds for evoking movement of the contralateral forelimb (Fig. 6A), the contralateral hindlimb (Fig. 6B), or the jaw (Fig. 6C). No ipsilateral forelimb or hindlimb movements were evoked from any animal.

\section{Effects of unilateral vibrissa trimming on frequency of dual forelimb-vibrissa movement sites}

A normal component of the output organization of rat M1 is the presence of some sites along the border region between the forelimb and vibrissa representations from which movement of both body parts can be evoked simultaneously (dual forelimbvibrissa movements). To determine the effects of vibrissa trimming on this aspect of M1 organization, the occurrence of such dual sites was expressed as a proportion of the total number of forelimb penetrations combined from all animals of the group, because the sizes and the mapping densities of the forelimb representations were similar across all groups (above). In the adult-control group, the frequency of dual movement sites in the left hemispheres was $11.5 \%$ (17 of 148 forelimb penetrations) and was similar to that in the right hemispheres $(10.4 \%, 10$ of 96 forelimb penetrations; Fig. 7). These values were similar to those obtained from the birth-trimmed group (Fig. 7), with 34 of 297 forelimb penetrations yielding dual movements in the left hemispheres $(11.5 \%)$ and 27 of 261 forelimb penetrations yielding dual movements in the right hemispheres $(10.3 \%)$. In contrast, in the adult-trimmed group, the frequency of dual movement sites dropped to $3.4 \%$ in the left hemispheres (5 of 146 forelimb sites) and $3.3 \%$ in the right hemispheres (4 of 121 forelimb sites).

\section{DISCUSSION}

The present results show that unilateral vibrissa trimming from birth alters the cortical vibrissa motor representation pattern in adult rat M1 bilaterally when revealed by electrical microstimulation techniques. The four principal findings are first, unilateral vibrissa trimming from birth, but not when initiated in adulthood, led to a significantly smaller-sized M1 vibrissa representation in the hemisphere contralateral to the trimmed vibrissae, with no evidence for concomitant changes in the size of the adjacent forelimb representation or the representation of the intact vibrissae in the opposite (ipsilateral) hemisphere. Second, in the contralateral hemispheres of the birth-trimmed group, an abnormal pattern of evoked vibrissa output was found in which bilateral or ipsilateral (intact) vibrissa movement predominated. Third, in both hemispheres of the birth-trimmed group, the current thresholds for eliciting movement of the trimmed vibrissae were significantly lower than normal. This effect was not evident in the adult-trimmed group. Fourth, there was one novel change in the 
A

\section{vibrissa-left MI}

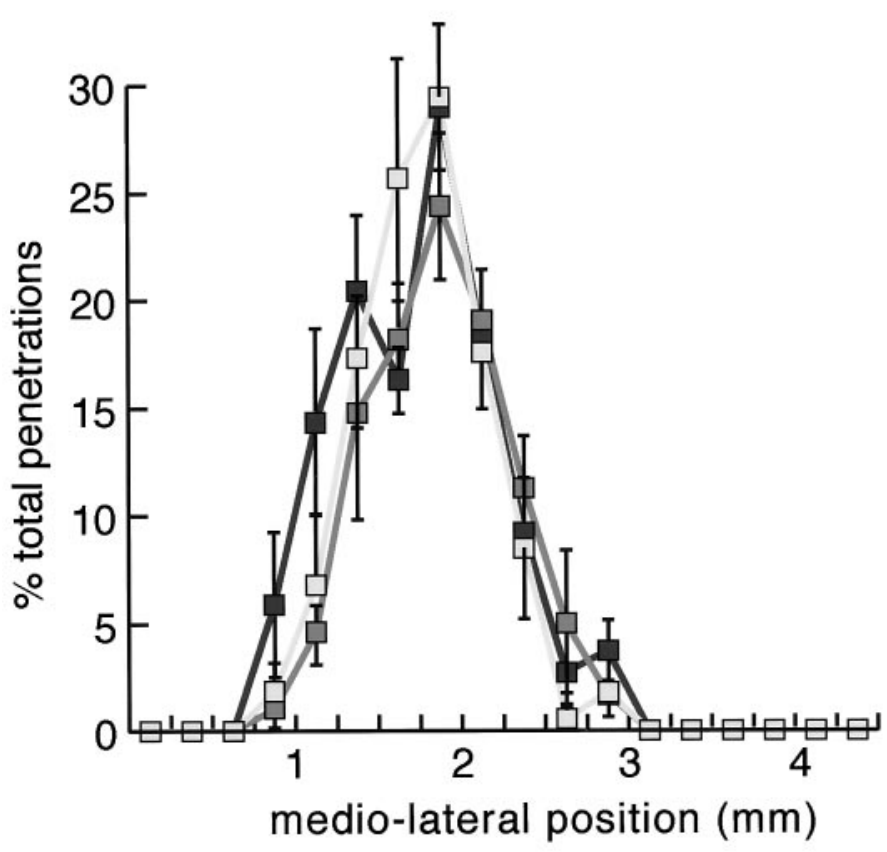

B

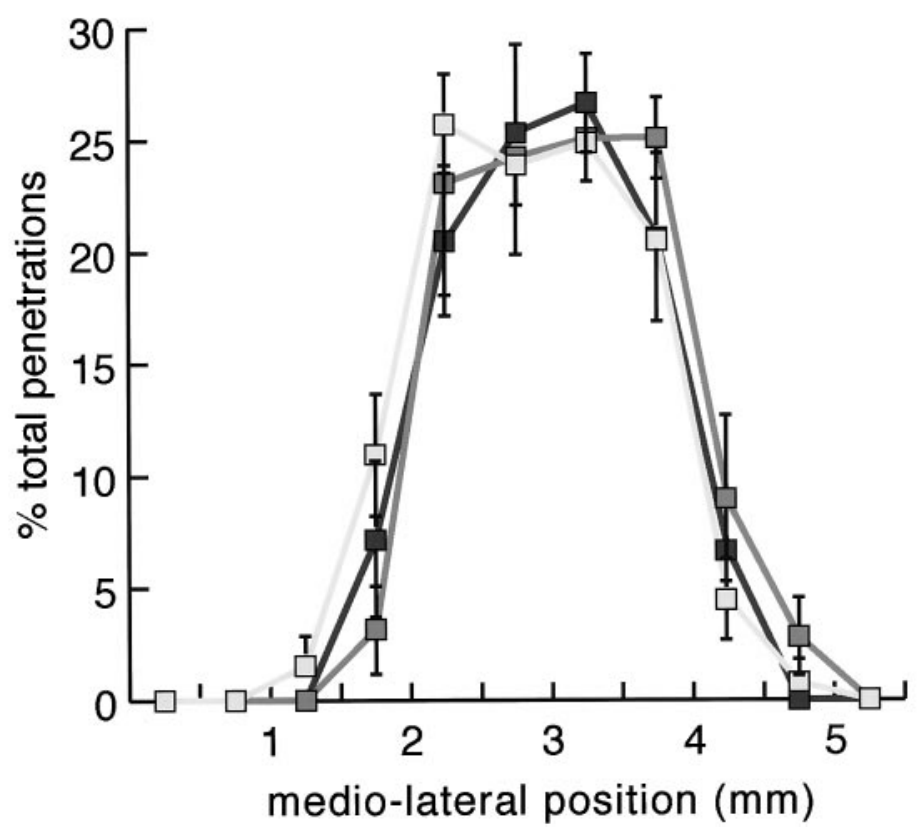

vibrissa-right MI

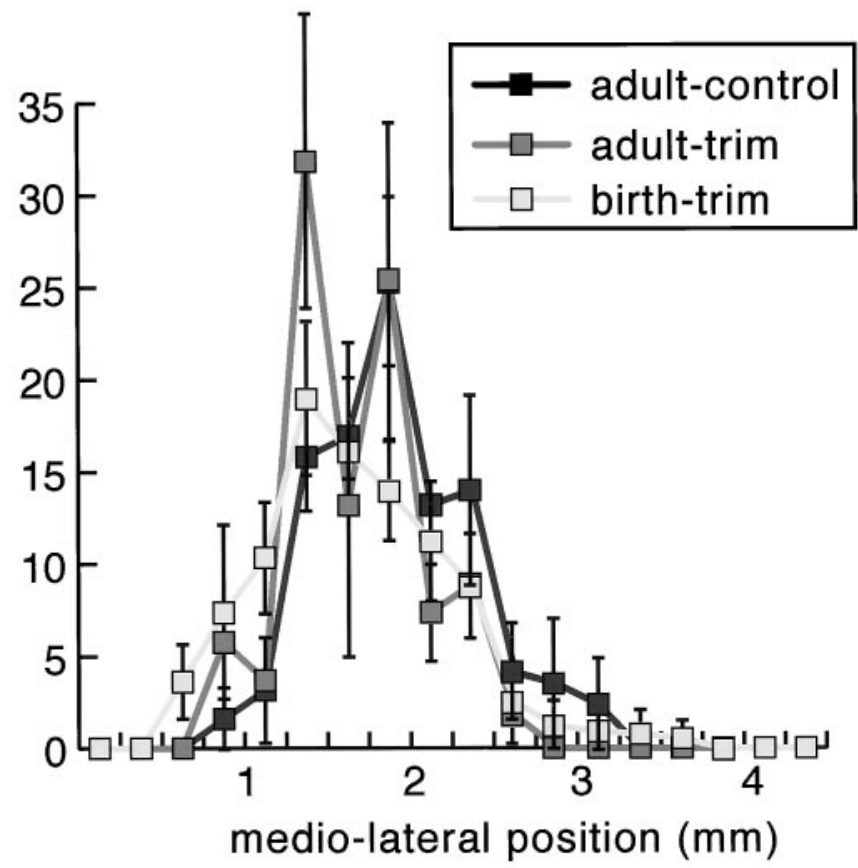

forelimb-right MI

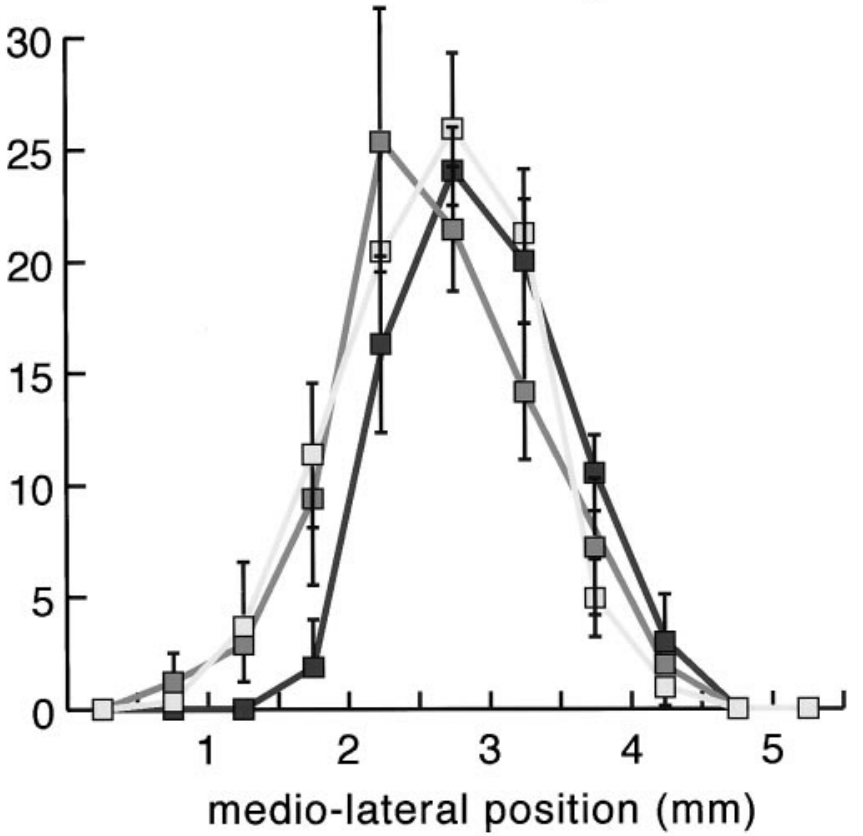

Figure 3. Comparisons of the mediolateral frequency distribution of penetrations eliciting vibrissa $(A)$ or forelimb $(B)$ movement between adult-control and vibrissa-trimmed groups. For each hemisphere, mediolateral position was distributed into $0.5 \mathrm{~mm}$ bins extending from the midline $(0 \mathrm{~mm})$ to 5.5 $\mathrm{mm}$ lateral of the midline, irrespective of anteroposterior coordinate. The number of penetrations falling into each bin was tallied and expressed as a percentage of the total penetrations $( \pm$ SEM). The mediolateral distribution of forelimb or vibrissa penetrations was highly variable; statistical comparisons across groups for each bin revealed no significant differences. Thus, vibrissa trimming did not overtly skew the relative positioning of M1 vibrissa and forelimb representations across the mediolateral extent of cortex.

adult-trimmed group, evident in the motor cortices of both hemispheres, which was not demonstrable in the birth-trimmed group: a decrease in the relative frequency of dual forelimb-vibrissa sites along the border region between these two movement representations. These main results differ in part from those reported in a similar study by Keller et al. (1996). However, their depriva- 
Adult-control
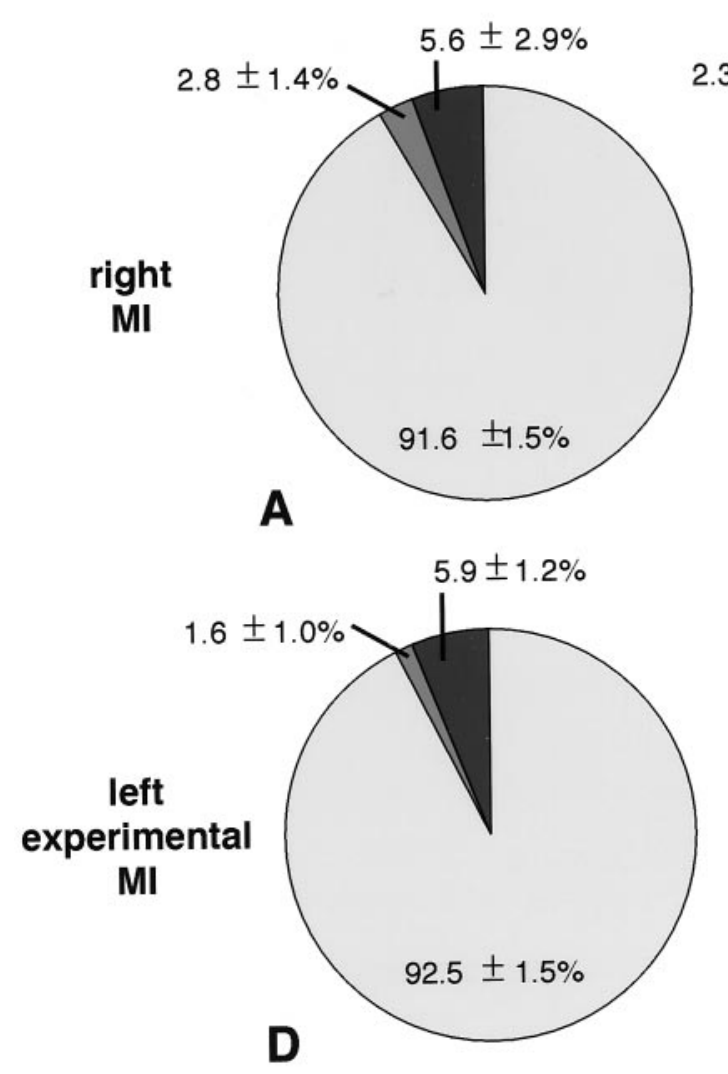

Adult-trimmed

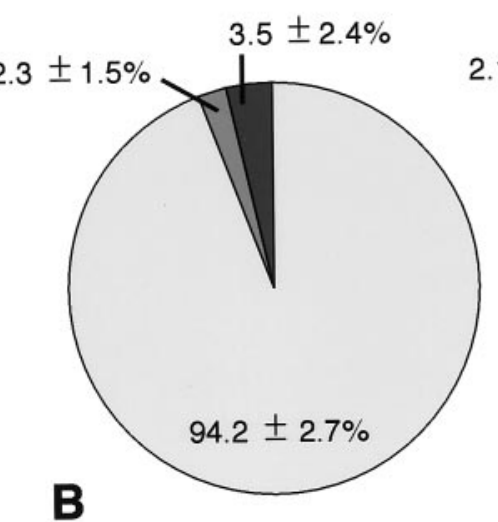

B

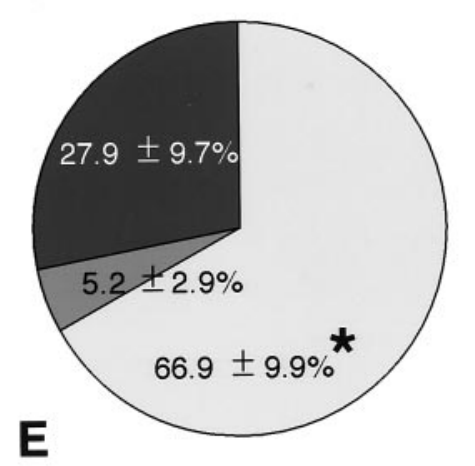

\section{Birth-trimmed}
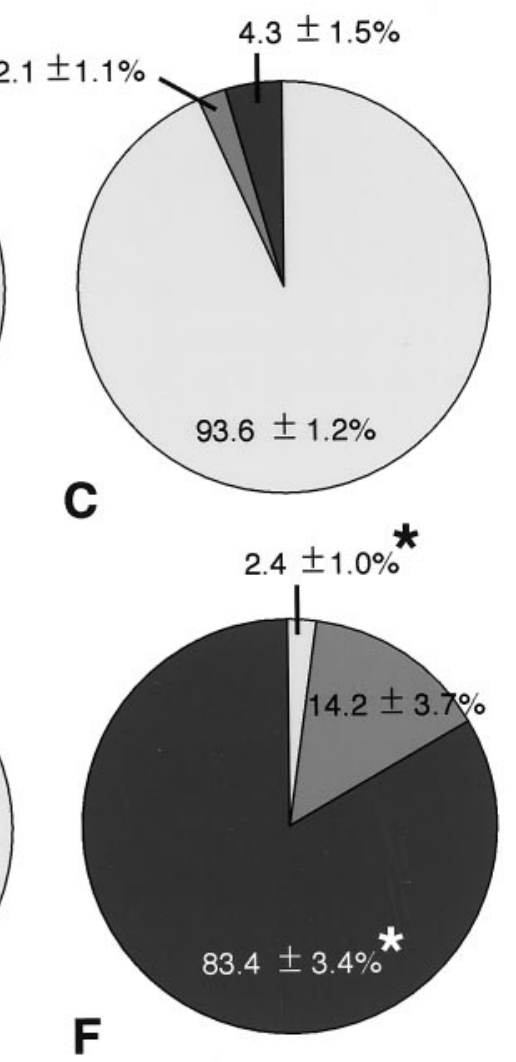

\section{contralateral vibrissa movement}

\section{ipsilateral vibrissa movement}

\section{bilateral vibrissa movement}

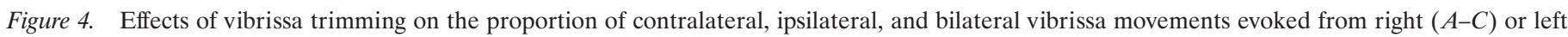

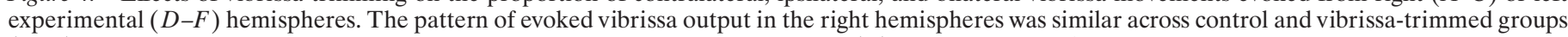

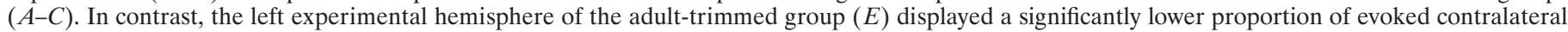

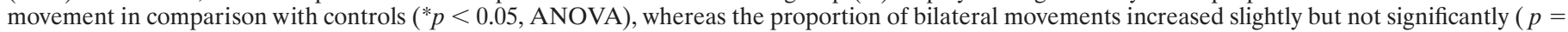

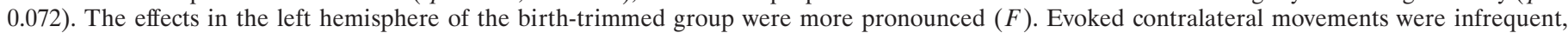
whereas bilateral movements predominated $(* p<0.0001$, ANOVA). Data are mean \pm SEM.

tion paradigm (bilateral whisker trimming) and duration of trimming was significantly different from those of the present study. Thus, not unexpectedly, the form of M1 plasticity, like other cortical areas studied, appears inextricably linked to the nature of the deprivation.

\section{What drives the changes to M1 vibrissa representations of the birth-trimmed group?}

The present results suggest that vibrissa-related tactile experience plays an instructional role in defining the cortical vibrissa motor representation during development, thus extending the well documented role for tactile experience in organizing somatosensory receptive field properties of neurons within the vibrissatrigeminal system (Simons and Land, 1987, 1994; Fox, 1992; Jacquin et al., 1995; Nicolelis et al., 1996). Such an influence of sensory experience on motor output organization has been demonstrated previously for development of other highly integrated sensory-motor behaviors. Auditory experience, for example, plays a crucial role in shaping the motor output circuits that lead to mature birdsong (Konishi, 1989). Nevertheless, the present experiments cannot discount the possibility that behavioral modifications of motor experience were also involved. Birth-trimmed animals may have adopted a behavioral asymmetry favoring the intact vibrissa hemiface for tactile exploration (Milani et al., 1989), which might lead to more active or purposeful whisking movement of the intact vibrissae. Use-dependent changes in M1 motor maps have been demonstrated in monkeys, whereby cortical representations of muscles engaged in a specific task expand, whereas representations of those not explicitly favored in the task contract (Nudo et al., 1996). A "use-dependent" hypothesis would be consistent with the smaller-sized motor representation of the trimmed vibrissae but inconsistent with the lack of any significant expansion of the motor representation of the intact vibrissae in the hemisphere contralateral to the intact vibrissae where this representation is normally found. However, the significantly in- 

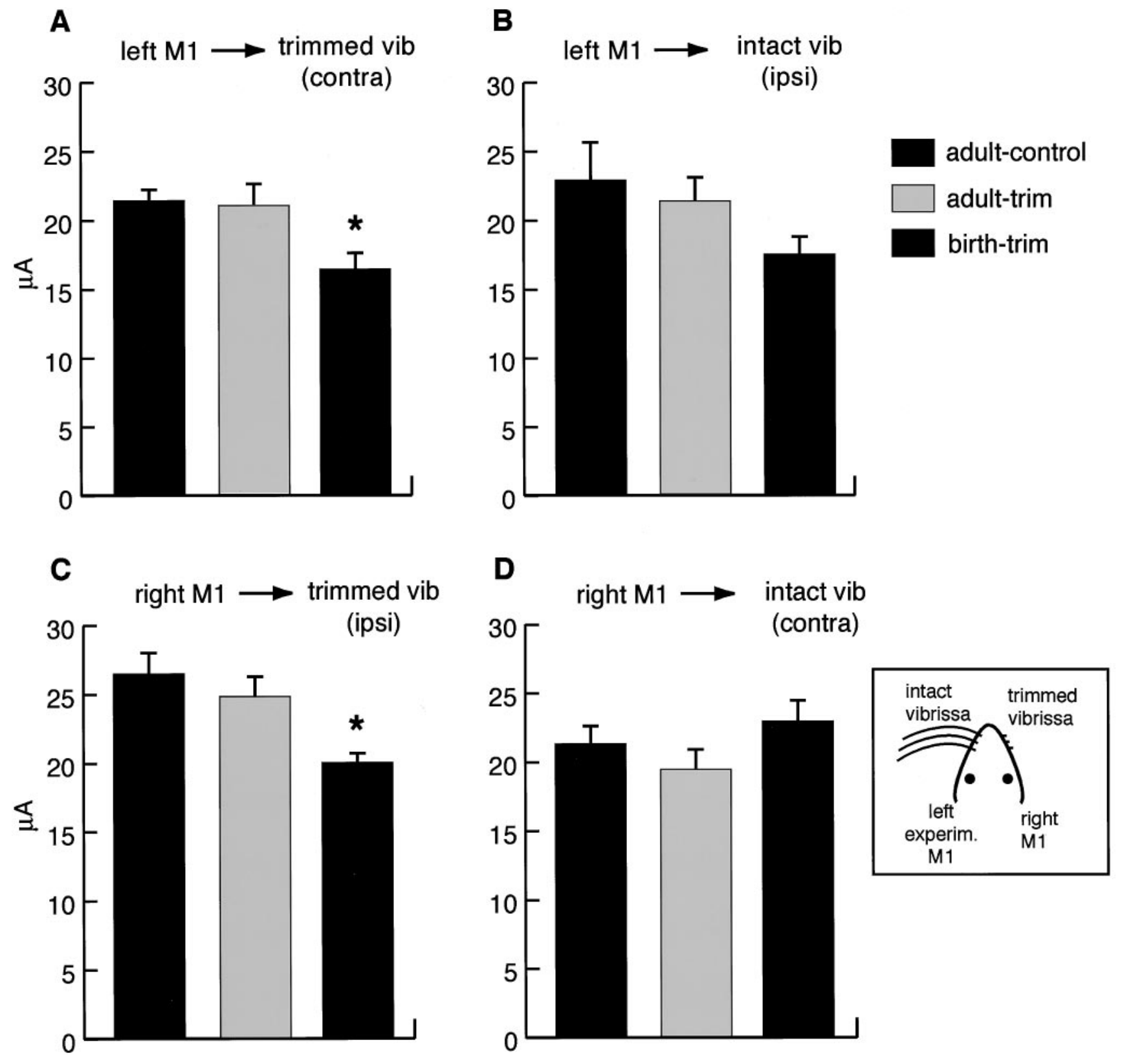

Figure 5. Across-group comparisons of current thresholds for evoking movement of the trimmed or intact set of vibrissa (vib) from either hemisphere. Current thresholds for evoking movement of the trimmed vibrissa, from either left experimental $(A)$ or right $(C)$ hemispheres, was significantly lower in the birth-trimmed group in comparison with controls $\left({ }^{*} p<0.05\right.$, ANOVA). Data are means + SEM. contra, Contralateral; ipsi, ipsilateral.

creased frequency of abnormal bilateral and ipsilateral (intact) vibrissa movement elicited from the left experimental M1 could be interpreted as an expansion of the motor representation of the intact vibrissa, which extended into the opposite hemisphere. Thus, either the characteristics of use-dependent changes in rat M1 representations may be constrained by different organizational principles in comparison with primates, one example being the significant overlap between parts of M1 and S1 (Wise and Donoghue, 1986), or motor use-dependent effects were not a major factor.

\section{Where is the substrate for altered M1 representations located?}

It is likely that M1 vibrissa cortex represents a principal gateway through which abnormal tactile experience gains access to motor output organization, with subsequent changes occurring at the level of M1 itself and/or within the terminal structures to which M1 vibrissa cortex projects. Vibrissa motor cortex receives extensive connections from S1 and S2 (Donoghue and Parham, 1983; Izraeli and Porter, 1995), which arise from layers that, in S1 of neonatally trimmed animals, display anatomical abnormalities in GABAergic circuitry (Micheva and Beaulieu, 1995a,b). Such anatomical alterations are evident bilaterally, strongly suggesting that M1 vibrissa cortex of both hemispheres receives abnormal activity from S1, which might be one basis for the bilateral effects observed in M1. Abnormal somatosensory feedback could also reach M1 directly through thalamic projections of the centrolateral nucleus or posterior complex (Donoghue and Parham, 1983; Miyashita et al., 1994), although effects of vibrissa trimming on 
A

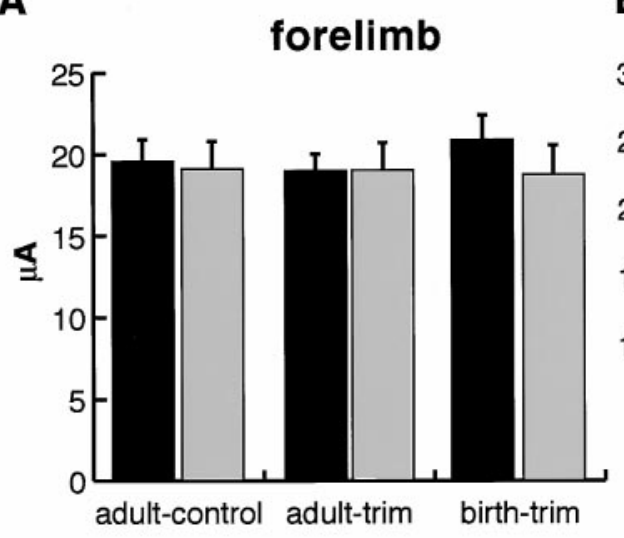

B

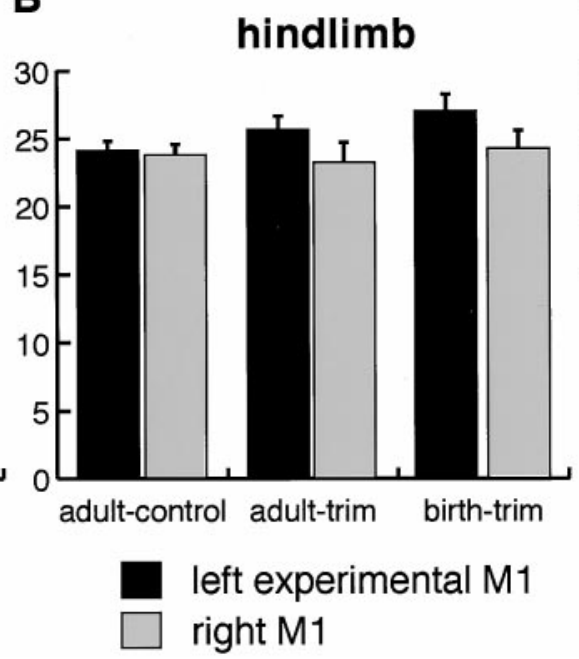

C

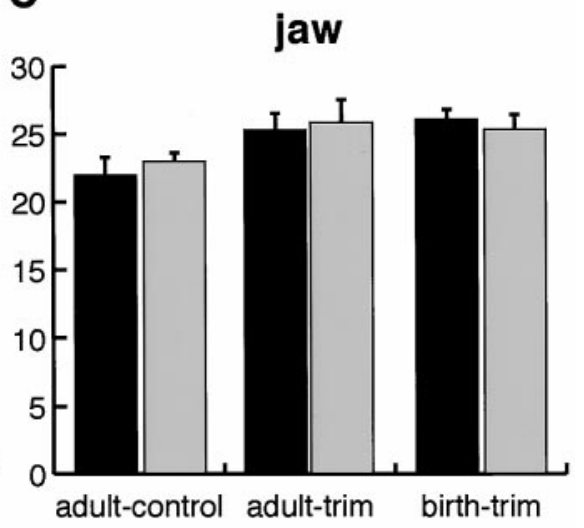

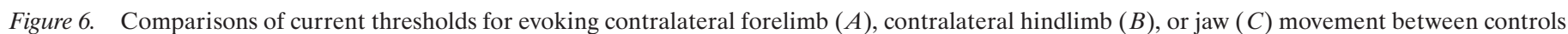
and vibrissa-trimmed groups. In both hemispheres, current thresholds were similar across groups. Data are means + SEM.

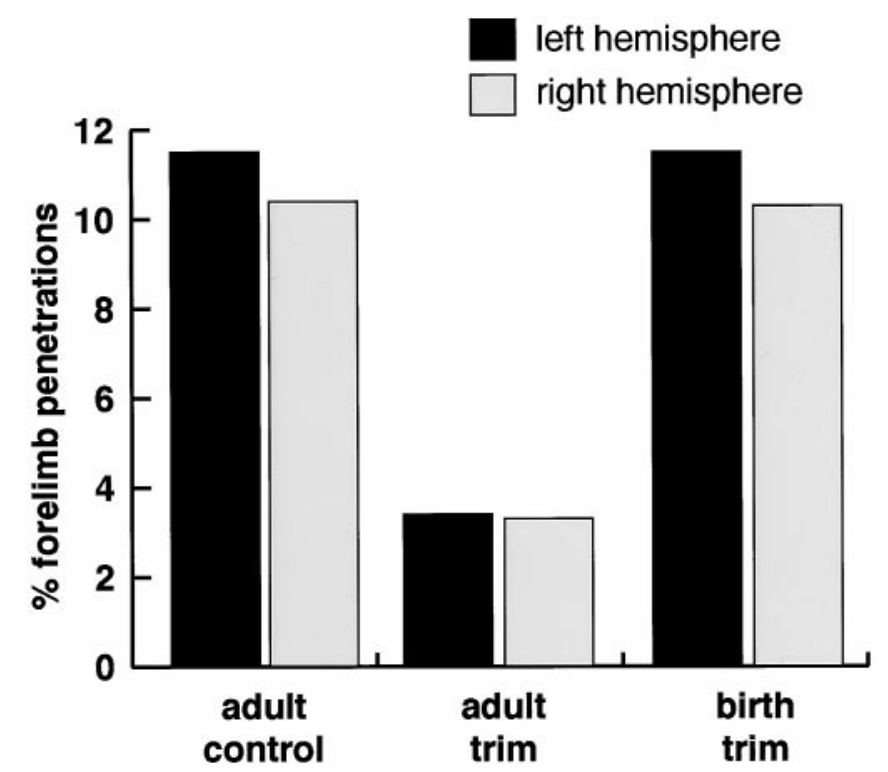

Figure 7. Proportion of dual-movement (forelimb and vibrissa) sites in control and vibrissa-trimmed groups. The occurrence of dual-movement sites was expressed as a percentage of total forelimb penetrations. Relative frequency of dual-movement sites was similar between control and birth-trimmed groups but was substantially reduced in both hemispheres of the adult-trimmed group.

these structures are unknown. Nevertheless, the present results do not explicitly demonstrate that altered representation patterns are necessarily supported by changes within M1 itself. Many subcortical areas receive connections from M1 vibrissa cortex (Porter and White, 1983; Miyashita et al., 1994) and display increased 2-deoxyglucose uptake after microstimulation-evoked vibrissa movement (Sharp and Evans, 1982). There is evidence that unilateral vibrissa trimming in adult rats changes the distribution of crossed nigrostriatal projections (Huston et al., 1986), which may indicate perturbations in sensory-gated motor functions of the basal ganglia (Lidksy et al., 1985), or other structures are also involved.

\section{Possible mechanisms}

The rat motor system, including M1, is structurally and functionally immature at birth (Welker, 1964; Schreyer and Jones, 1982; Miller, 1988). Although the precise factors that guide the maturation of cortical circuits are incompletely understood, a role for patterned activity in refining immature neural circuitry has been well documented (Antonini and Stryker, 1993; Katz and Shatz, 1996). The more overt effects evident in the birth-trimmed group in comparison with the adult-trimmed group may therefore reflect an altered sequence of maturational refinements in connectivity patterns induced by abnormal somatosensory feedback.

The smaller-sized vibrissa area could arise from an abnormally restricted tangential distribution of neurons projecting to the brainstem. The mature distribution pattern of layer $\mathrm{V}$ corticof $\mathrm{u}-$ gal neurons in rat M1 emerges from one in which neurons project initially to a common set of subcortical targets before elimination of all but the appropriately targeted axon branch during early postnatal periods (O'Leary and Koester, 1993). This process may be influenced by locally specific patterns of activity (O'Leary, 1992). Thus, abnormally patterned activity focused on the incipient vibrissa motor cortex may have heightened elimination of axons projecting to the brainstem during the early postnatal period of refinement. An alternative possibility is that an abnormally high-threshold, but normally sized, vibrissa representation masked much of the area from which vibrissa movements could be evoked by the techniques used. This seems unlikely, however, because the current threshold for evoking movement of the trimmed vibrissa was significantly lower in comparison with the other groups. Such threshold changes were specific, because there were no differences across groups in current thresholds for evoking movements of other major body parts or for the intact vibrissae evoked from either hemisphere.

Given the lack of expansion of the forelimb representation in compensation for the reduced vibrissa area, it is not immediately clear what "fills in" that part of cortex that would normally occupy the full vibrissa representation. It is unlikely that vibrissa trimming led to an overall smaller neocortex. Monkeys bilaterally enucleated during fetal life exhibit changes in sizes of some visual cortical areas without affecting the overall dimensions of neocortex (Dehay et al., 1996). Thus, either the medially adjacent M1 
representation of the eye and eyelid expanded, although this was not overtly obvious, or another, neighboring cortical area expanded. Histochemical markers reveal no areal changes in S1 barrel cortex after vibrissa trimming (Micheva and Beaulieu, 1995b), leaving the possibility that the medially situated motor area AGm, corresponding to a secondary motor field (Donoghue and Wise, 1982), may have expanded.

One interpretation of reduced thresholds for evoking movement of the trimmed vibrissa is that synaptic strengths were increased by vibrissa trimming. A role for activity-influenced changes in expression or uptake of growth factors has been suggested (Katz and Shatz, 1996) in the establishment of terminal axonal branching (Cabelli et al., 1995; Cohen-Cory and Fraser, 1995) and regulation of synaptic strengths (Lohof et al., 1993; Kang and Schuman, 1995; Figurov et al., 1996). Vibrissa stimulation in mice, for example, leads to increased expression of brain-derived neurotrophic factor in S1 (Rocamora et al., 1996). Thus, long-term activity-dependent changes in growth factors could lead to altered synaptic microcircuitry within the vibrissa motor cortex or other sites.

One of the most dramatic findings was the abnormally high proportion of bilateral vibrissa movements elicited from the left experimental M1. In normal adult rats, the typical pattern of contralateral vibrissa movement elicited by electrical stimulation of M1 changes rapidly to bilateral vibrissa movement on picrotoxin administration to M1 of the opposite hemisphere (Toldi et al., 1996). This suggests that the abnormal bilateral movements result from alterations in functional callosal connectivity. Changes in GABAergic circuitry of M1 ipsilateral to the trimmed vibrissa could lead to disinhibition of callosal input, yielding bilateral M1 activation on focal stimulation of the experimental side. It is also possible that abnormal activity changed the normal, developmental refinement in the distribution of callosal projection neurons (Koralek and Killackey, 1990) or led to an abnormal retention of a set of transient callosal connections, which, in other areas, are normally eliminated during early postnatal development (Innocenti, 1986). Alternatively, bilateral movements could arise from an abnormal innervation of, or maintenance of transient projections to, brainstem structures with direct projections to the ipsilateral facial nerve nucleus (Miyashita and Mori, 1995). Neonatal vibrissa removal, for example, stabilizes a normally transient projection to $\mathrm{S} 1$ from a thalamic auditory relay nucleus (Nicolelis et al., 1991). That the magnitude of abnormal vibrissal movement was far greater in the birth-trimmed animals in comparison with the adult-trimmed ones may indicate that different mechanisms are involved depending on the stage at which the perturbation is introduced.

The adult-trimmed group displayed some similar changes, although of much lesser magnitude, consistent with previous conclusions that mature M1 representations retain a capacity for functional modification under the influence of changing sensory feedback (Gellhorn and Hyde, 1953; Sanes et al., 1992). The basis for such effects could be long-term changes in synapse number as a result of altered experience (Kleim et al., 1996) or changes in synaptic efficacies of preexisting connections (Diamond et al., 1993; Donoghue et al., 1996) through long-term, activitydependent changes in neurochemical levels. In adult rodent S1, for example, enhancing or reducing activity by vibrissa stimulation or trimming leads to changes in levels of glutamic acid decarboxylase (Akhtar and Land, 1991), growth factors (Rocamora et al., 1996), and immediate-early genes (Steiner and Gerfen, 1994). The one novel change evident in the adult- trimmed group was a reduction in the proportion of dual forelimb-vibrissa sites along the common border. Dual movements could result from direct activation of abutting populations of corticofugal neurons projecting to brainstem or spinal cord and/or indirect activation of such cells through local projections that straddle the border (Weiss and Keller, 1994; Huntley, 1997). The reduction in dual-movement sites may reflect long-term depression of the functional efficacy of those projections situated very locally at the border (Hess and Donoghue, 1996), whereas increased efficacy of those that extend for longer distances has been proposed for rapid border shifts after peripheral nerve lesion (Jacobs and Donoghue, 1991; Huntley, 1997). In contrast to effects on adult motor map reorganization induced by facial nerve lesion (Sanes et al., 1988), there was no overt evidence that vibrissa trimming in the adult-trimmed group led to an expansion of the forelimb representation. Thus, the mechanisms underlying sensory experience-related changes to M1 maps are likely to be distinct from those underlying changes induced by peripheral motor nerve damage, because an intact vibrissa motor output pathway, even in the face of abnormal sensory feedback, appears sufficient for maintaining the relative positioning and size of the adjacent forelimb area. Alternatively, it is possible that subtle border shifts did occur in individual animals but were limited enough to produce expanded forelimb areas still within the range of normal variability and, thus, went undetected.

\section{Significance}

Previous behavioral studies of birth-trimmed animals have shown a correlation between sensory discrimination tasks that animals fail to learn and ones in which animals also display abnormal whisking frequencies (Carvell and Simons, 1996). Vibrissa motor cortex is thought to play a role in the initiation or modulation of whisking frequency, which is generated subcortically (Carvell et al., 1996). Thus, the present results suggest that abnormalities in M1 organization contribute to such sensory-motor deficits. Interestingly, adult-trimmed animals do not display comparable behavioral or vibrissa motor deficits (Carvell and Simons, 1996), which may reflect the current observation that the motor cortices of such adult-trimmed animals were more resistant to the effects of vibrissa trimming. The discrepancy in the severity of effects between birth- and adult-trimmed groups both in behavioral performance and in organization of M1 representations suggests that M1 displays a critical period of susceptibility to abnormal sensory feedback from the vibrissae. The structural and functional organization of rat S1 barrel cortex displays well characterized periods of susceptibility to a variety of peripheral manipulations (Kaas et al., 1983), including vibrissa trimming (Fox, 1992). S1 may therefore dictate the timing of such periods for both sensory and motor maps. It is also likely that M1 and other motor structures display their own critical periods of susceptibility to sensorimotor perturbations (Walton et al., 1992). It remains to be determined whether the effects on M1 representations observed in the birth-trimmed group are reversible, but the observation that such animals do not regain normal discriminative capacity, even with months of renewed vibrissa growth (Carvell et al., 1996), suggests that they are not (but see Keller et al., 1996). This would imply that normal sensory experience at early stages of development is a critical requirement for normal motor output organization and performance. 


\section{REFERENCES}

Akhtar ND, Land PW (1991) Activity-dependent regulation of glutamic acid decarboxylase in the rat barrel cortex: effects of neonatal versus adult sensory deprivation. J Comp Neurol 307:200-213.

Antonini A, Stryker MP (1993) Rapid remodeling of axonal arbors in the visual cortex. Science 260:1819-1821.

Asanuma H, Arnold AP (1975) Noxious effects of excessive currents used for intracortical microstimulation. Brain Res 96:103-107.

Asanuma H, Arnold AP, Zarzecki P (1976) Further study on the excitation of pyramidal tract cells by intracortical microstimulation. Exp Brain Res 26:443-462.

Baddeley AJ, Gundersen HJG, Cruz-Orive LM (1986) Estimation of surface area from vertical sections. J Microsc 142:259-276.

Cabelli RJ, Hohn A, Shatz CJ (1995) Inhibition of ocular dominance column formation by infusion of NT-4/5 or BDNF. Science 267:1662-1666.

Carvell GE, Simons DJ (1990) Biometric analyses of vibrissal tactile discrimination in the rat. J Neurosci 10:2638-2648.

Carvell GE, Simons DJ (1996) Abnormal tactile experience early in life disrupts active touch. J Neurosci 16:2750-2757.

Carvell GE, Miller SA, Simons DJ (1996) The relationship of vibrissal motor cortex unit activity to whisking in the awake rat. Somatosens Mot Res 13:115-127.

Cheney PD, Fetz EE (1985) Comparable patterns of muscle facilitation evoked by individual corticomotoneuronal (CM) cells and by single intracortical microstimuli in primates: evidence for functional groups of CM cells. J Neurophysiol 53:786-804.

Clark SA, Allard T, Jenkins WM, Merzenich MM (1988) Receptive fields in the body-surface map in adult cortex defined by temporally correlated inputs. Nature 332:444-445.

Cohen-Cory S, Fraser SE (1995) Effects of brain-derived neurotrophic factor on optic axon branching and remodeling in vivo. Nature 378:192-194.

Dehay C, Giroud P, Berland M, Killackey H, Kennedy H (1996) Contribution of thalamic input to the specification of cytoarchitectonic cortical fields in the primate: effects of bilateral enucleation in the fetal monkey on the boundaries, dimensions, and gyrification of striate and extrastriate cortex. J Comp Neurol 367:70-89.

Diamond ME, Armstrong-James M, Ebner FF (1993) Experiencedependent plasticity in adult rat barrel cortex. Proc Natl Acad Sci USA 90:2082-2086.

Dolan S, Cahusac PMB (1996) Differential effect of whisker trimming on excitatory and inhibitory transmission in primary somatosensory cortex of the adult rat in vivo. Neuroscience 70:79-92.

Donoghue JP, Parham C (1983) The afferent connections of the lateral agranular field of the rat motor cortex. J Comp Neurol 217:390-404.

Donoghue JP, Sanes JN (1988) Organization of adult motor cortex representation patterns following neonatal forelimb nerve injury in rats. J Neurosci 8:3221-3232.

Donoghue JP, Wise SP (1982) The motor cortex of the rat: cytoarchitecture and microstimulation mapping. J Comp Neurol 212:76-88.

Donoghue JP, Suner S, Sanes JN (1990) Dynamic organization of primary motor cortex output to target muscles in adult rats. II. Rapid reorganization following motor nerve lesions. Exp Brain Res 79:492-503.

Donoghue JP, Leibovic SJ, Sanes JN (1992) Organization of the forelimb area in squirrel monkey primary motor cortex: representation of individual digit, wrist, and elbow muscles. Exp Brain Res 89:1-19.

Donoghue JP, Hess G, Sanes JN (1996) Substrates and mechanisms for learning in motor cortex. In: Acquisition of motor behavior (Bloedel J, Ebner T, Wise SP, eds), pp 363-386. Cambridge, MA: MIT.

Ezure K, Oshima T (1985) Lateral spread of neuronal activity within the motor cortex investigated with intracellular responses to distant epicortical stimulation. Jpn J Physiol 35:223-249.

Figurov A, Pozzo-Miller LD, Olafsson P, Wang T, Lu B (1996) Regulation of synaptic responses to high-frequency stimulation and LTP by neurotrophins in the hippocampus. Nature 381:706-709.

Fox K (1992) A critical period for experience-dependent synaptic plasticity in rat barrel cortex. J Neurosci 12:1826-1838.

Fox K (1994) The cortical component of experience-dependent synaptic plasticity in the rat barrel cortex. J Neurosci 14:7665-7679.

Gellhorn E, Hyde J (1953) Influence of proprioception on map of cortical responses. J Physiol (Lond) 122:371-385.

Guic-Robles E, Valdivieso C, Guajardo G (1989) Rats can learn a roughness discrimination using only their vibrissal system. Behav Brain Res 31:285-289.

Hess G, Donoghue JP (1996) Long-term depression of horizontal connections in rat motor cortex. Eur J Neurosci 8:658-665.

Huntley GW (1997) Correlation between patterns of horizontal connectivity and the extent of short-term representational plasticity in rat motor cortex. Cereb Cortex 7:143-156.

Huntley GW, Jones EG (1991) Relationship of intrinsic connections to forelimb movement representations in monkey motor cortex: a correlative anatomic and physiological study. J Neurophysiol 66:390-413.

Huston JP, Morgan S, Lange KW, Steiner H (1986) Neuronal plasticity in the nigrostriatal system of the rat after unilateral removal of vibrissae. Exp Neurol 93:380-389.

Innocenti GM (1986) General organization of callosal connections in the cerebral cortex. In: Cerebral cortex, Vol 5 (Jones EG, Peters A, eds), pp 291-354. New York: Plenum.

Izraeli R, Porter LL (1995) Vibrissal motor cortex in the rat: connections with the barrel field. Exp Brain Res 104:41-54.

Jacobs KM, Donoghue JP (1991) Reshaping the cortical motor map by unmasking latent intracortical connections. Science 251:944-945.

Jacquin MF, Rhoades RW, Klein BG (1995) Structure-function relationships in rat brainstem subnucleus interpolaris. XI. Effects of chronic whisker trimming from birth. J Comp Neurol 356:200-224.

Jenkins IH, Brooks DJ, Nixon PD, Frackowiak SJ, Passingham RE (1994) Motor sequence learning: a study with positron emission tomography. J Neurosci 14:3775-3790.

Jones EG, Coulter JD, Hendry SHC (1978) Intracortical connectivity of architectonic fields in the somatic sensory, motor and parietal cortex of monkeys. J Comp Neurol 181:291-348.

Kaas JH, Merzenich MM, Killackey HP (1983) The reorganization of the somatosensory cortex following peripheral nerve damage in adult and developing mammals. Annu Rev Neurosci 14:137-167.

Kang H, Schuman EM (1995) Long-lasting neurotrophin-induced enhancement of synaptic transmission in the adult hippocampus. Science 267:1658-1662.

Karni A, Meyer G, Jezzard P, Adams MM, Turner R, Ungerleider LG (1995) Functional MRI evidence for adult motor cortex plasticity during motor skill learning. Nature 377:155-158.

Katz LC, Shatz CJ (1996) Synaptic activity and the construction of cortical circuits. Science 274:1133-1138.

Keller A, Weintraub ND, Miyashita E (1996) Tactile experience determines the organization of movement representations in rat motor cortex. NeuroReport 7:2373-2378.

Kleim JA, Lussnig E, Schwarz ER, Comery TA, Greenough WT (1996) Synaptogenesis and FOS expression in the motor cortex of the adult rat after motor skill learning. J Neurosci 16:4529-4535.

Konishi M (1989) Birdsong for neurobiologists. Neuron 3:541-549.

Koralek K-A, Killackey HP (1990) Callosal projections in rat somatosensory cortex are altered by early removal of afferent input. Proc Natl Acad Sci USA 87:1396-1400.

Lemon RN, Porter R (1976) Afferent input to movement-related precentral neurones in conscious monkeys. Proc R Soc Lond [Biol] 194:313-339.

Lemon RN, Muir RB, Mantel GWH (1987) The effects upon the activity of hand and forearm muscles of intracortical stimulation in the vicinity of corticomotor neurones in the conscious monkey. Exp Brain Res 66:621-637.

Li X, Glazewski S, Lin X, Elde R, Fox K (1995) Effect of vibrissae deprivation on follicle innervation, neuropeptide synthesis in the trigeminal ganglion, and S1 barrel cortex plasticity. J Comp Neurol 357:465-481.

Lidksy TI, Manetto C, Schneider JS (1985) A consideration of sensory factors involved in motor functions of the basal ganglia. Brain Res Rev 9:133-146.

Lohof AM, Ip NY, Poo MM (1993) Potentiation of developing neuromuscular synapses by the neurotrophins NT-3 and BDNF. Nature 363:350-353.

Micheva KD, Beaulieu C (1995a) An anatomical substrate for experience-dependent plasticity of the rat barrel field cortex. Proc Natl Acad Sci USA 92:11834-11838.

Micheva KD, Beaulieu C (1995b) Neonatal sensory deprivation induces selective changes in the quantitative distribution of GABAimmunoreactive neurons in the rat barrel field cortex. J Comp Neurol 361:574-584.

Milani H, Steiner H, Huston JP (1989) Analysis of recovery from behav- 
ioral asymmetries induced by unilateral removal of vibrisae in the rat. Behav Neurosci 103:1067-1074.

Miller MW (1988) Development of projection and local circuit neurons in neocortex. In: Cerebral cortex, Vol 7 (Peters A, Jones EG, eds), pp 133-175. New York: Plenum.

Miyashita E, Mori S (1995) The superior colliculus relays signals descending from the vibrissal motor cortex to the facial nerve nucleus in the rat. Neurosci Lett 195:69-71.

Miyashita E, Keller A, Asanuma H (1994) Input-output organization of the rat vibrissal motor cortex. Exp Brain Res 99:223-232.

Nicolelis MA, Chapin JK, Lin RCS (1991) Neonatal whisker removal in rats stabilizes a transient projection from the auditory thalamus to the primary somatosensory cortex. Brain Res 567:133-139.

Nicolelis MA, Baccala LA, Lin RC, Chapin JK (1995) Sensorimotor encoding by synchronous neural ensemble activity at multiple levels of the somatosensory system. Science 268:1353-1358.

Nicolelis MA, De Oliveira LMO, Lin RCS, Chapin JK (1996) Active tactile exploration influences the functional maturation of the somatosensory system. J Neurophysiol 75:2192-2196.

Nudo RJ, Jenkins WM, Merzenich MM, Prejean T, Grenda R (1992) Neurophysiological correlates of hand preference in primary motor cortex of adult squirrel monkeys. J Neurosci 12:2918-2947.

Nudo RJ, Milliken GW, Jenkins WM, Merzenich MM (1996) Usedependent alterations of movement representations in primary motor cortex of adult squirrel monkeys. J Neurosci 16:785-807.

O'Leary DDM (1992) Development of connectional diversity and specificity in the mammalian brain by pruning of collateral projections. Curr Opin Neurobiol 2:70-77.

O'Leary DDM, Koester SE (1993) Development of projection neuron types, axon pathways, and patterned connections of the mammalian cortex. Neuron 10:991-1006.

Pascual-Leone A, Dang N, Cohen LG, Brasil-Neto JP, Cammarota A, Hallett M (1995) Modulation of muscle responses evoked by transcranial magnetic stimulation during the acquisition of new fine motor skills. J Neurophysiol 74:1037-1045.

Pavlides D, Miyashita E, Asanuma H (1993) Projection from the sensory to the motor cortex is important in learning motor skills in the monkey. J Neurophysiol 70:733-741.

Porter LL, White EL (1983) Afferent and efferent pathways of the vibrissal region of primary motor cortex in the mouse. J Comp Neurol 214:279-289.

Rocamora N, Welker E, Pascual M, Soriano E (1996) Upregulation of BDNF mRNA expression in the barrel cortex of adult mice after sensory stimulation. J Neurosci 16:4411-4419.

Sakamoto T, Porter LL, Asanuma H (1987) Long-lasting potentiation of synaptic potentials in the motor cortex produced by stimulation of the sensory cortex in the cat: a basis of motor learning. Brain Res 413:360-364.

Sanes JN, Suner S, Lando JF, Donoghue JP (1988) Rapid reorganization of adult rat motor cortex somatic representation patterns after motor nerve injury. Proc Natl Acad Sci USA 85:2003-2007.

Sanes JN, Suner S, Donoghue JP (1990) Dynamic organization of primary motor cortex output to target muscles in adult rats I. Long-term patterns of reorganization following motor or mixed peripheral nerve lesions. Exp Brain Res 79:479-491.

Sanes JN, Wang J, Donoghue JP (1992) Immediate and delayed changes of rat motor cortical output representation with new forelimb configurations. Cereb Cortex 2:141-152.

Schreyer DJ, Jones EG (1982) Growth and target finding by axons of the corticospinal tract in prenatal and postnatal rats. Neuroscience 7:1837-1853.

Sessle BJ, Wiesendanger M (1982) Structural and functional definition of the motor cortex in the monkey (Macaca fascicularis). J Physiol (Lond) 323:245-265.

Sharp FR, Evans K (1982) Regional $\left({ }^{14} \mathrm{C}\right)$ 2-deoxyglucose uptake during vibrissae movements evoked by rat motor cortex stimulation. J Comp Neurol 208:255-287.

Simons DJ, Land PW (1987) Early experience of tactile stimulation influences organization of somatic sensory cortex. Nature 326:694-697.

Simons DJ, Land PW (1994) Neonatal whisker trimming produces greater effects in nondeprived than deprived thalamic barreloids. J Neurophysiol 72:1434-1437.

Steiner H, Gerfen CR (1994) Tactile sensory input regulates basal and apomorphine-induced immediate-early gene expression in rat barrel cortex. J Comp Neurol 344:297-304.

Toldi J, Laskawi R, Landgrebe M, Wolff JR (1996) Biphasic reorganization of somatotopy in the primary motor cortex follows facial nerve lesions in adult rats. Neurosci Lett 203:179-182.

Walton KD, Lieberman D, Llinás A, Begin M, Llinás RR (1992) Identification of a critical period for motor development in neonatal rats. Neuroscience 51:763-767.

Weiss DS, Keller A (1994) Specific patterns of intrinsic connections between representation zones in the rat motor cortex. Cereb Cortex 4:205-214.

Welker WI (1964) Analysis of sniffing of the albino rat. Behaviour 12:223-244.

Wise SP, Donoghue JP (1986) Motor cortex of rodents. In: Cerebral cortex, Vol 5 (Jones EG, Peters A, eds), pp 243-270. New York: Plenum.

Zarzecki P (1989) Influence of somatosensory cortex on different classes of cat motor cortex output neuron. J Neurophysiol 62:487-494. 